\title{
Crop and environmental attributes underpinning genotype by environment interaction in synthetic-derived bread wheat evaluated in Mexico and Australia
}

\author{
M. Fernanda Dreccer ${ }^{\mathrm{A}, \mathrm{F}}$, Scott C. Chapman ${ }^{\mathrm{B}}$, Francis C. Ogbonnaya ${ }^{\mathrm{C}}$, \\ M. Gabriela Borgognone ${ }^{\mathrm{D}}$, and R. M. Trethowan ${ }^{\mathrm{E}}$

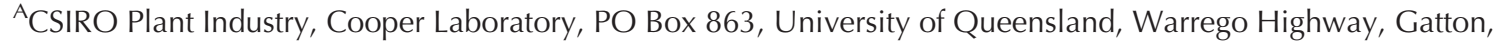 \\ Qld 4343, Australia. \\ ${ }^{B}$ CSIRO Plant Industry, Queensland Bioscience Precinct, 306 Carmody Road, St Lucia, Qld 4067, Australia. \\ C Primary Industries Research Victoria (PIRVic), Department of Primary Industries, Horsham Centre, \\ Private Bag 260, Horsham, Vic. 3401, Australia. \\ DQueensland Department of Primary Industries and Fisheries, PO Box 102, 203 Tor Street, Toowoomba, \\ Qld 4350, Australia. \\ EUniversity of Sydney, Plant Breeding Institute, PMB 11, Camden, NSW 2570, Australia. \\ FCorresponding author. Email: fernanda.dreccer@csiro.au
}

\begin{abstract}
Synthetic backcrossed-derived bread wheats (SBWs) from CIMMYT were grown in the north-west of Mexico (CIANO) and sites across Australia during 3 seasons. A different set of lines was evaluated each season, as new materials became available from the CIMMYT crop enhancement program. Previously, we have evaluated both the performance of genotypes across environments and the genotype $\times$ environment interaction $(\mathrm{G} \times \mathrm{E})$. The objective of this study was to interpret the $\mathrm{G} \times \mathrm{E}$ for yield in terms of crop attributes measured at individual sites and to identify the potential environmental drivers of this interaction. Groups of SBWs with consistent yield performance were identified, often comprising closely related lines. However, contrasting performance was also relatively common among sister lines or between a recurrent parent and its SBWs.

Early flowering was a common feature among lines with broad adaptation and/or high yield in the northern Australian wheatbelt, while yields in the southern region did not show any association with the maturity type. Lines with high yields in the southern and northern regions had cooler canopies during flowering and early grain filling. Among the SBWs with Australian genetic backgrounds, lines best adapted to CIANO were tall $(>100 \mathrm{~cm})$, with a slightly higher ground cover. These lines also displayed a higher concentration of water-soluble carbohydrates in the stem at flowering, which was negatively correlated with stem number per unit area when evaluated in southern Australia (Horsham). Possible reasons for these patterns are discussed.

Selection for yield at CIANO did not specifically identify the lines best adapted to northern Australia, although they were not the most poorly adapted either. In addition, groups of lines with specific adaptation to the south would not have been selected by choosing the highest yielding lines at CIANO. These findings suggest that selection at CIMMYT for Australian environments may be improved by either trait based selection or yield data combined with trait information. Flowering date, canopy temperature around flowering, tiller density, and water-soluble carbohydrate concentration in the stem at flowering seem likely candidates.
\end{abstract}

Additional keywords: synthetic backcrossed-derived bread wheat, drought, breeding, genotype $\times$ environment interaction.

\section{Introduction}

The use of synthetic backcrossed-derived bread wheats (SBWs) has increased the genetic diversity of the CIMMYT(International Maize and Wheat Improvement Centre) breeding program compared with the levels present in modern cultivars (Warburton et al. 2006). SBWs are produced by crossing primary synthetic wheats with adapted wheat cultivars. Primary synthetic wheats are produced by inter-specific hybridisation of the original donors of the wheat genome: Triticum turgidum L., donor of the AB genome, and the wild progenitor Aegilops tauschii L., donor of the D genome. Increased diversity could further improve the crop's ability to adapt to different environmental conditions. This adaptability is often observed in breeding trials as large genotype by environment interaction $(\mathrm{G} \times \mathrm{E})$, and is generally of greater significance when factors such as drought are present (Reynolds et al. 2002). Large 
$\mathrm{G} \times \mathrm{E}$ adds uncertainty to the identification of superior lines, as lines tend to rank differently among environments (e.g. Cooper and deLacy 1994; de la Vega and Chapman 2001).

In a previous paper, we gave an account of the yield performance of SBWs bred at CIMMYT and grown in trials in the north-west of Mexico at the Centro de Investigaciones Agrícolas del Noroeste (CIANO) and at sites across Australia over 3 seasons (Dreccer et al. 2007). Several SBWs, crossed to both Australian and CIMMYT backgrounds, outperformed the local benchmark checks at sites from the northern end of the Australian wheatbelt, with reduced success at more southern locations. In general, lines that succeeded in northern Australia and/or CIANO were different from those that performed well in southern Australia, confirming a large $\mathrm{G} \times \mathrm{E}$. One of the objectives of this study was to determine if groups of lines could be identified underlying the $\mathrm{G} \times \mathrm{E}$. The previously observed $\mathrm{G} \times \mathrm{E}$ for yield was also interpreted in terms of crop attributes measured at individual sites and in relation to main environmental drivers, by examining the relationship with weather data captured during different crop developmental stages across sites. In addition, the pedigree of lines was examined to make inferences about its influence on overall performance.

\section{Materials and methods}

\section{Germplasm and trial description}

A detailed account of both the germplasm used and the trials grown is given in Dreccer et al. (2007). In summary, Australia received 'shipments' of different SBWs from CIMMYT during 3 consecutive years, consisting of $c$. 100 advanced lines $\left(\mathrm{F}_{7}\right)$ per year, selected from a larger set tested in Mexico. SBWs were multiplied during quarantine and in a summer nursery, thus the lines tested were $F_{7}: 10$. SBWs had been top- and backcrossed to CIMMYT cultivars in the first two shipments and to released Australian cultivars in the third. Australian recurrent parents were representative of the breeding progress in different regions, e.g. Kulin in the west, Kennedy and Cunningham in the north, and Janz, Silverstar, RAC710, and RAC655 representing southern areas. The selection methodology has been described in detail elsewhere (Trethowan 2004; Trethowan et al. 2005).

Each shipment of SBWs, including check cultivars, was sown at CIMMYT and at different locations around Australia in field experiments; plot size varied from $4.8 \mathrm{~m}^{2}$ at CIANO to $9.6 \mathrm{~m}^{2}$ in Australia. At CIANO, trials were sown in paired rows on raised beds at c. 300 plants $/ \mathrm{m}^{2}$. In Australia, trials were sown at densities of $100-150$ plants $/ \mathrm{m}^{2}$. Trials were fertilised and maintained free from weeds, insects, and diseases. CIMMYT's drought screening of the SBWs was carried out at CIANO (Table 1). CIANO is located in the Sonoran desert and the trials were grown on receding moisture; irrigation was only applied before planting. In 2004, one trial was planted late in order to expose plants to higher temperatures; this heat-stress trial was irrigated throughout the season. In Australia, the lines were evaluated in locations across the country, the majority under rainfed conditions (Table 1). In the northern region, where crops are generally dependent on summer rainfall, the average annual rainfall over the past 45 years was $599 \mathrm{~mm}$ at Roma,

Table 1. Coordinates and acronyms of trials and summary statistics of 'core' SBWs and checks yields Checks are Hartog in METShip1 and METShip2; Janz, Kennedy, Silverstar, and Cunningham in METShip3

\begin{tabular}{|c|c|c|c|c|c|c|c|c|c|c|}
\hline Site & Year & Trial acronym & Latitude & Longitude & $\begin{array}{l}\text { Yield SBWs } \\
(\mathrm{t} / \mathrm{ha})\end{array}$ & s.d. & $n$ & $\begin{array}{l}\text { Yield checks } \\
\text { (t/ha) }\end{array}$ & s.d. & $n$ \\
\hline \multicolumn{11}{|c|}{ METShipl } \\
\hline CIANO & 2000 & 02CIANO & 27.35 & -109.33 & 2.54 & 0.23 & 84 & 2.52 & - & 1 \\
\hline Horsham Irrigated & 2002 & 02HshamIRR & -36.65 & 142.10 & 5.17 & 1.08 & 84 & 5.84 & - & 1 \\
\hline Biloela & 2002 & 02Bilo & -24.38 & 150.52 & 3.45 & 0.35 & 84 & 3.61 & - & 1 \\
\hline Roma & 2002 & 02Roma & -26.57 & 148.79 & 1.21 & 0.16 & 84 & 1.22 & - & 1 \\
\hline Merredin & 2002 & 02Mdin & -31.50 & 118.22 & 0.39 & 0.09 & 84 & 0.38 & - & 1 \\
\hline Wongan Hills & 2002 & 02WHills & -30.84 & 116.73 & 1.72 & 0.20 & 84 & 1.93 & - & 1 \\
\hline \multicolumn{11}{|c|}{ METShip2 } \\
\hline CIANO & 2002 & 03CIANO & 27.35 & -109.33 & 3.51 & 0.24 & 49 & 3.22 & - & 1 \\
\hline Horsham Irrigated & 2003 & 03HshamIRR & -36.65 & 142.10 & 6.10 & 0.64 & 49 & 6.75 & - & 1 \\
\hline Horsham Rainfed & 2003 & 03HshamRF & -36.65 & 142.10 & 4.18 & 0.29 & 49 & 3.97 & - & 1 \\
\hline Biloela & 2003 & 03Bilo & -24.38 & 150.52 & 2.85 & 0.16 & 49 & 2.95 & - & 1 \\
\hline Roma & 2003 & 03Roma & -26.57 & 148.79 & 2.30 & 0.21 & 49 & 2.22 & - & 1 \\
\hline Narrabri & 2003 & 03Nbri & -30.34 & 149.75 & 5.22 & 0.25 & 49 & 5.01 & - & 1 \\
\hline Biloela & 2004 & 04Bilo & -24.38 & 150.52 & 5.14 & 0.28 & 49 & 5.26 & - & 1 \\
\hline Roma & 2004 & 04Roma & -26.57 & 148.79 & 2.62 & 0.44 & 49 & 2.94 & - & 1 \\
\hline Narrabri & 2004 & 04Nbri & -30.34 & 149.75 & 5.95 & 0.52 & 49 & 5.36 & - & 1 \\
\hline \multicolumn{11}{|c|}{ METShip3 } \\
\hline CIANO & 2004 & 04CIANO & 27.35 & -109.33 & 4.15 & 0.53 & 23 & 3.88 & 0.33 & 4 \\
\hline CIANO Heat & 2004 & 04CIANOHT & 27.35 & -109.33 & 1.69 & 0.45 & 23 & 1.48 & 0.25 & 4 \\
\hline Horsham Irrigated & 2004 & 04HshamIRR & -36.65 & 142.10 & 4.29 & 0.44 & 23 & 4.80 & 0.41 & 4 \\
\hline Horsham Rainfed & 2004 & 04HshamRF & -36.65 & 142.10 & 1.09 & 0.42 & 23 & 1.36 & 0.49 & 4 \\
\hline Biloela & 2004 & 04Bilo & -24.38 & 150.52 & 4.88 & 0.34 & 23 & 5.23 & 0.39 & 4 \\
\hline Roma & 2004 & 04Roma & -26.57 & 148.79 & 2.67 & 0.55 & 23 & 3.01 & 0.33 & 4 \\
\hline Narrabri & 2004 & 04Nbri & -30.34 & 149.75 & 5.78 & 0.67 & 23 & 5.56 & 0.19 & 4 \\
\hline
\end{tabular}


$687 \mathrm{~mm}$ at Biloela, and $654 \mathrm{~mm}$ at Narrabri. Locations in southwestern Australia, Merredin and Wongan Hills, have a winterdominant rainfall pattern, with historic average annual rainfall of 366 and $304 \mathrm{~mm}$, respectively. Horsham, in the south-east, also has a predominantly winter-rainfall pattern and an average annual rainfall of $448 \mathrm{~mm}$. At Horsham, two adjacent trials were run each year, one rainfed, the other receiving supplementary irrigation around anthesis and grain filling to generate a higher yielding environment.

\section{Environmental descriptors and traits}

Environmental descriptors were calculated for each site at specific crop stages based on available weather data. A base temperature of $0^{\circ} \mathrm{C}$ was used for all thermal time calculations. Briefly, the vegetative stage (when the apex is differentiating leaves) was approximated as 600 degree-days after sowing, including 100 degree-days from sowing to emergence (Miralles et al. 2001). The duration of the period of grain number definition spanned from rapid spike growth, which was assumed to start 300 degree-days before flowering, roughly from flag leaf appearance, to 100 degree-days postflowering to account for grain set. The grain-filling period was approximated as 600 degree-days from grain set (Loss et al. 1989). Descriptors of photoperiod or temperature $\left({ }^{\circ} \mathrm{C}\right)$ were: average daylength $(\mathrm{h})$ and temperature during the vegetative stage; average temperature during flowering and grain filling; frequency of occurrence of days when maximum temperature was equal to or above $30^{\circ} \mathrm{C}$ during flowering and grain filling; frequency of occurrence of days when minimum temperature was equal to or below $0^{\circ} \mathrm{C}$ during flowering, i.e. frost days. The photothermal quotient $\left(\mathrm{MJ} / \mathrm{m}^{2}\right.$. day. $\left.{ }^{\circ} \mathrm{C}\right)$ was calculated as the ratio between average daily radiation and average temperature during flowering (Fischer 1985), with a base temperature of $0^{\circ} \mathrm{C}$. The fraction of diffuse radiation during flowering was calculated as a function of atmospheric transmissivity, based on actual daily photosynthetically active radiation and the calculated daily extraterrestrial radiation constant (Goudriaan and van Laar 1994).

An index of water availability (WA, mm), i.e. water availability from sowing to the periods mentioned above, was determined as the amount of water from rainfall plus irrigation plus plant-available water in the soil measured at sowing. The potential evapotranspiration $(\mathrm{ET}, \mathrm{mm})$ was calculated using the Priestley-Taylor equation with the parameterisation used by the Australian Bureau of Meteorology (Wang et al.2001). The vapour pressure deficit $(\mathrm{kPa})$ around flowering or grain filling was calculated as described in Dreccer et al. (2007). The relationship between water supply and atmospheric demand was estimated as the ratio between the cumulative potential evapotranspiration and water availability from rainfall and irrigation between sowing and each particular crop stage (ET : WA).

In Australia, flowering dates were recorded for at least one location in the south (Horsham) and another in the north (Roma and/or Biloela) every season. Flowering was recorded when 50\% of the spike population had at least $50 \%$ anthers extruded, and was scored in categories (1, early; 2 , average; 3 , late; 4 , very late) during 2002 and 2003 and as days after planting in 2004. At CIANO, heading dates were recorded in categories in 2004
(1, early; 2, average; 3, late). Height (including spike) was measured in the standing crop shortly after anthesis. Height was recorded in $\mathrm{cm}$ (Horsham 2004) or in categories (CIANO 2004: 1, below $70 \mathrm{~cm} ; 2,70-100 \mathrm{~cm} ; 3$, above $100 \mathrm{~cm})$. At CIANO in 2004, ground cover was scored as 1, low; 5, high.

In the rainfed trial at Horsham in 2004, several other variables were measured. The canopy stress index $\left(\mathrm{CSI},{ }^{\circ} \mathrm{C} / \mathrm{kPa}\right)$, defined as the difference between canopy and air temperature, normalised by vapour pressure deficit (Idso et al. 1981; Idso 1982), was calculated around anthesis and early grain filling, based on thermal images (Rodriguez et al. 2005). Images were obtained between 11 a.m. and 1 p.m. with a ThermaCam P40 (FLIR Systems AB, Danderyd, Sweden), taken from $2.5 \mathrm{~m}$ above ground level in a nadir direction. Air temperature and relative humidity above the canopy were simultaneously recorded with a Vaisala HM70 (Vaisala, Helsinki, Finland). Biomass cuts of 0.1 and $0.2 \mathrm{~m}^{2}$ were made at anthesis (DC65) and maturity, respectively. Stems and spikes were counted and harvest index calculated on a dry-weight basis. From the anthesis biomass cut, the levels of water-soluble carbohydrates in the stems and sheaths were determined by near-infrared reflectance spectroscopy. Selected samples to cover the range of observations were used for calibration in ethanol extraction (see van Herwaarden et al. 1998 for details) followed by determination of total water-soluble carbohydrates in the extract, using the anthrone method of Yemm and Willis (1954) with fructose as the standard.

\section{Experimental design and data analyses}

Full details of the experimental design and analyses are given by Dreccer et al. (2007). Trials were designed as randomised complete blocks with neighbour balance or as incomplete block designs, with 2-3 replicates. The trial layouts at CIANO corresponding to SBWs from the first two shipments were in a series of small side-by-side experiments. Therefore, for the multi-environment trial (MET) analyses, they were considered as separate trials in the same environment. An environment is defined as a site $\times$ year combination or a site $\times$ year $\times$ management combination (e.g. irrigated or rainfed trials at Horsham). For the purpose of statistical analyses, data were organised into 3 groups of METs containing germplasm from Shipment 1 (METShip1), Shipment 2 (METShip2), or Shipment 3 (METShip 3) (see trial grouping in Table 1). Each shipment was analysed separately as they contained different sets of SBWs.

Data for each of the 3 shipments were analysed using spatial mixed models for MET analyses. This method first determines an adequate spatial model for each trial, and then fits a factor analytic-model to the combined data while maintaining the spatial models previously determined (Smith et al. 2001). Best linear unbiased predictors (BLUPs) of yield for each genotype in each site were obtained from the model described.

A graphical representation of the multiplicative component of the factor-analytic model, where both the environmental loadings and the variety scores are displayed on the same graph, can be obtained. These graphs or biplots help to show the relationships among lines (scores), among environments (loadings), and between lines and environments (e.g. Fig. 1). In the biplots, 2 sites have a more positive genetic correlation as 
the angle between the vectors becomes more acute. The performance of a line at a particular site can be compared by projecting a perpendicular from the line to the site vector. Lines better adapted to a particular site are positioned on and towards the end of the site vectors, while those less adapted are scattered in the space opposite to the site vectors. Average lines or lines that are poorly fitted in the biplot fall close to the origin. Lines that are close to each other perform similarly in terms of the characteristic under study.

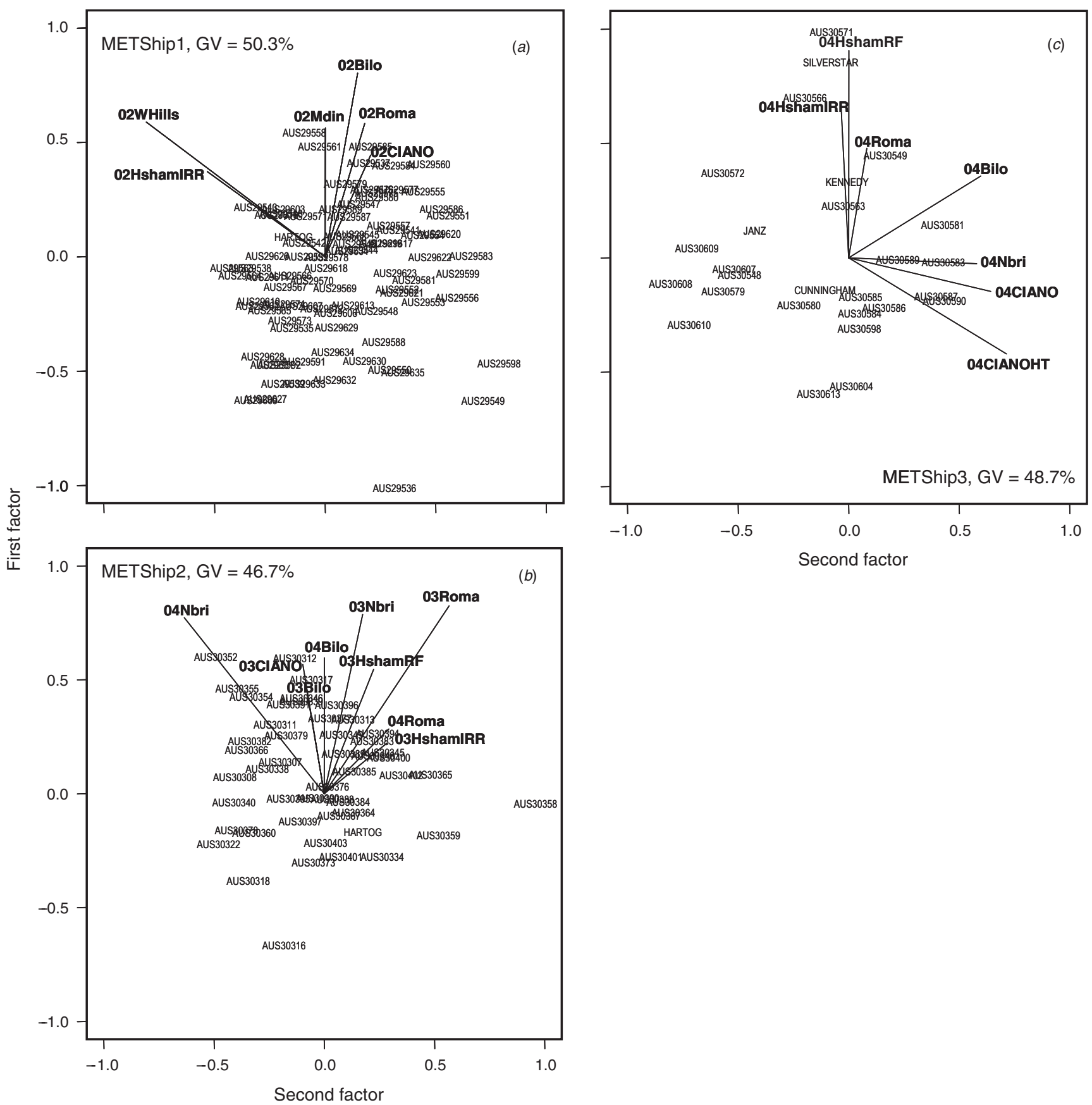

A large number of lines was tested and included in the spatial mixed models analyses that produced the genetic correlation biplot (Fig. 1) (Dreccer et al. 2007). However, only those common to all sites, or 'core' lines, were considered for further analysis in relation to traits. The yield BLUPs of core lines, obtained from the previous analysis, were used as the basis for clustering analysis. Clustering analyses were conducted using squared Euclidean distance as the proximity measure and Ward's method as the fusion criterion. These data are 
presented as heat maps, where the colour of each cell represents the magnitude of the standardised difference between the line and the site mean yield, calculated by subtracting the mean and dividing by the standard deviation. Heat maps were drawn using the software R v 2.2 (R Development Core Team 2006).

Principal component analysis (PCA) based on standardised variables was used to investigate the associations between lines in particular groups (scores) and traits measured at different sites (yield, flowering dates, etc.). PCA is a multivariate method that explains the variance-covariance structure of $p$ variables with $k$ linear combinations of the original variables, where $k$ is smaller than $p$. The principal components with eigenvalues greater than one are mentioned. The interpretation of the biplots produced by PCA analysis is similar to that of the factor analytic biplots explained above.

\section{Results and discussion}

\section{Groups of core lines underlying the $G \times E$ interaction}

The average percentage of genetic variance explained by the factor analytic models with 2 factors was $50.3 \%$ for METShip 1 , $46.7 \%$ for METShip2, and 48.7\% for METShip3 (Dreccer et al. 2007). Although all lines present in each trial were used to obtain the estimates of genetic variance, only those common to all sites within a METShip, or core lines, are represented in Fig. 1. One of the aims of this research was to determine if groups of lines could be identified that contribute to the underlying $\mathrm{G} \times \mathrm{E}$. This was addressed by examining yield and other traits from core lines, to make the comparisons more robust (Table 1). Pedigrees and yield estimates of the core lines per site are listed in the Accessory Publication.

In 2002, the Wongan Hills and Horsham irrigated trials were not well correlated with the other trials (Fig. 1a), as demonstrated by the near $90^{\circ}$ angle between the environment vectors of these 2 trials compared with the remaining trials. In METShip2 (Fig. 1b), the trials were more evenly distributed, with the poorest correlations between 04Nbri and 04Roma or 03HshamIRR trials. METShip3 demonstrated the broadest range of environments as indicated by the largest angles between environment vectors (Fig. 1c).

Based on grain yield, the lines in each METShip were separated into groups that displayed a consistent behaviour across environments; this information is presented in the heat maps (Fig. 2). The number of clusters used in each METShip was arbitrarily based on consistent yield performance of the lines in the group and consideration was given to differential expression of the other traits studied. The proportion of the $\mathrm{G} \times \mathrm{E}$ sum of squares that was explained by the genotypic grouping was $55 \%$, $45 \%$, and $51 \%$ in METShip 1, 2, and 3, respectively. In METShip1 (84 SBWs plus cv. Hartog), 2 main clusters with subgroups were identified (Fig. $2 a$ ). The first cluster consisted of broadly adapted lines (Groups 1 and 5) and lines performing slightly better at CIANO, northern wheatbelt locations (Roma and Biloela), and Merredin in Western Australia (Group 4). These trends for Group 1 members can be seen in their position in the upper left quadrant of the biplot (Fig. 1a) where their projections onto environment vectors indicate better than average yield in all environments. The second biggest cluster, comprising Groups 2, 6, and 3, represented either poorly adapted lines (Group 2) or lines with better relative performance under irrigation in Horsham and/or in Wongan Hills, which at other locations were either average (Group 3) or poor (Group 6). In 02HshamIRR, lines with broad (Group 1) or specific adaptation (Group 6) yielded c. 14\% over the site mean (Table 2 and Fig. 2). In northern locations, Group 5 lines, with better specific adaptation, yielded $19 \%$ and $12 \%$ over the site mean in 02Roma and 02Bilo, respectively. This compares favourably with the mostly broadly adapted Group 1 lines, which yielded $0 \%$ and $7 \%$ over the site mean at these respective locations.

The core lines from METShip2 (49 lines plus cv. Hartog) were divided into 4 groups based on the cluster analysis (Figs $1 b$ and $2 b$ ). The first split separated Groups 3 and 1, comprising entries that generally performed below the site mean (see genotype scores in biplot Fig. 1b), from Groups 2 and 4, which generally performed above the mean. Group 3 departed from Group 1, and 2 from 4, largely on the basis of above-average performance at Biloela in both years and in an early planting at Narrabri in 2004, compared with a relatively poorer performance at Horsham under irrigation. Group 4 contained 4 lines displaying broad adaptation. The change in mean yield between the poorest and the best performing groups within a location was in the order of 9-16\%, with the exception of Roma, which ranged from a $13 \%$ difference in 2003 (late planting) to $29 \%$ in 2004 (early planting). In METShip2, no lines showing specific adaptation to southern environments were apparent.

In METShip3, 23 SBWs were assessed, along with Janz, Kennedy, Silverstar, and Cunningham, which were among the Australian recurrent parents used to develop the SBWs (Figs 1c and $2 c$ ). This contrasts with the evaluation of the first two shipments where only cv. Hartog was grown both in Mexico and across Australia. The check cultivars in METShip 3 were always within the bounds of the scores of the synthetics and were not deemed to be 'driving' the large variation in Fig. $1 c$. The first two groups represented lines that performed either consistently below the site means across locations (Group 1) or poorly at CIANO (Group 2). Group 1 included Janz, 5 of its derivatives, and 3 SBWs backcrossed to lines of southern origin. Group 2 included Kennedy, Silverstar, and $3 \mathrm{SBWs}$ backcrossed to southern lines (RAC655, RAC710, and Janz) that are located towards the top of the biplot (Fig. 1c). In contrast, Group 3 included lines with above-average performance at CIANO and Narrabri, poor performance at Horsham, and average yield in Biloela and Roma. The group comprised Cunningham, 2 of its derivatives, and most Kennedy-derived lines. The change in mean yield between the worst and best performing groups within a location was in the order of $13-19 \%$, except at the two sites with lowest yield. There, the difference was in the order of $50 \%$ at 04 HorshamRF and $39 \%$ at CIANOHT.

\section{Pedigree influence on line clustering based on yield}

The question of whether clusters of lines could largely be ascribed to different pedigrees is important, as a positive association may have implications for future selection decisions. Two interesting aspects of the suggested link between pedigree and yield performance of the lines were observed. First, although clusters within a METShip tended to have a strong pedigree component, sister lines frequently 

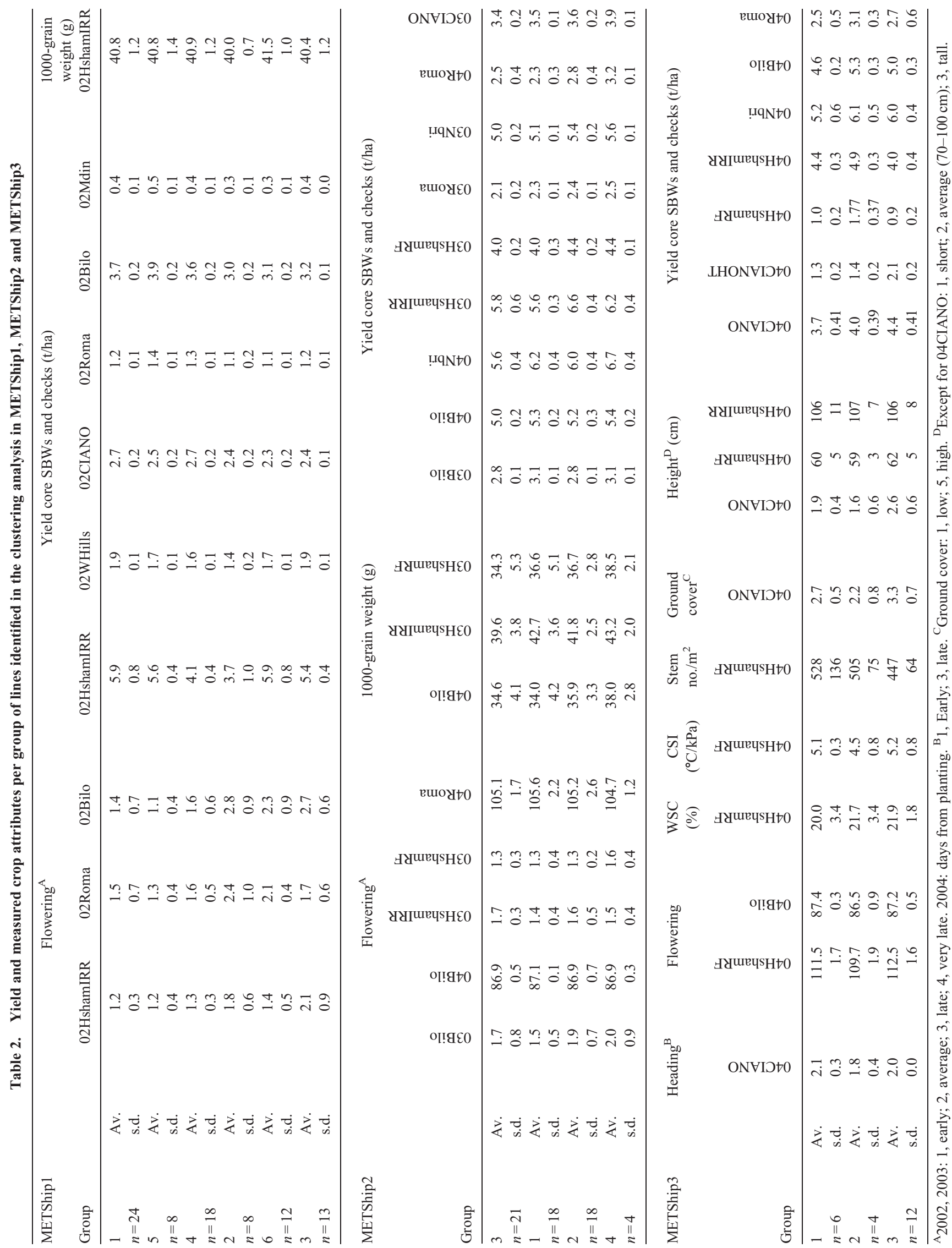
displayed contrasting performance. For instance, in METShip1, sister lines from the families CHEN/AEGILOPS TAUSCHII// 2*WEAVER (e.g. AUS29543 and AUS29539) and CHIL/ $2 *$ STAR/5/CNDO/R143//ENTE/MEXI_2/3/AEGILOPSTAU SCHII/4/WEAVER (AUS29616 and AUS29598) were represented in both the better and poorer adapted groups (Group $1 v$. Group 2) (Figs 1a, 2a). METShip2 consisted mainly of 3 SBW families. In the larger cluster $(23$ sister lines), sisters from the cross PASTOR/3/ALTAR 84/ AEGILOPS TAUSCHII//OPATA were split between the below-average yield Group 3 and the above-average yield Group 2 (Fig. 2b). Similarly, 3 sister lines from the cross CROC_1/AEGILOPS TAUSCHII (224)//OPATA/3/PASTOR were part of the best-performing group (Group 4) while 2 of them were among the worst (Group 3). This pattern likely indicates some degree of random selection during line development at CIANO for traits conferring specific adaptation to Australian environments.

The influence of the recurrent parent on performance can be seen in METShip1, where the primary synthetic CROC_1/ AEGILOPS TAUSCHII (205) crossed to the cv. Kauz was backcrossed to different recurrent parents and produced SBWs spread across groups of contrasting performance (see AUS-CROC_1-(205) pedigrees in Fig. 2a). For instance, when backcrossed to Galvez/Weaver, the SBWs clustered in Group 5, with above-average performance in northern areas; however, when backcrossed to SASIA or NL682, they either performed poorly (Group 2), or relatively better in the south compared with the north or CIANO (Groups 6 and 3). An important aspect to this finding is the observation that the shipments of SBWs based on Mexican backgrounds (METShip1 and 2) contained groups of lines with broad adaptation, while the shipment in Australian background (METShip3) did not (Fig. 2). The Mexican recurrent parents such as Kauz, Pastor, Weaver, and Opata have been shown to have good adaptation across global spring wheat trials (Braun et al. 1996; Smale et al. 2002; Mathews et al. 2006).

A more complex picture, arising from the interaction between the recurrent parent and the selection process at CIMMYT, can be seen in METShip3 (Fig. 2c). First, the cv. Kennedy (Group 2) performed differently from its derivatives (Group 3) (Fig. 2c, Accessory Publication). Second, recurrent parents that would be considered adapted to the south, such as RAC710 and RAC655, did produce SBWs that are also adapted to the north, such as AUS30571 and AUS30566 in Group 2. The divergence in performance between recurrent parents and SBWs is likely to be the consequence of the selection process at CIMMYT, including the shuttle breeding program (Rajaram and van Ginkel 2001; Dreccer et al. 2007), allowing key regions of the genome driving specific adaptation to Australian environments to be replaced by genome fragments from the synthetic ancestry.

\section{The link between traits and environmental drivers of the $G \times E$}

Groups of SBWs with consistent performance in each METShip were identified. In this section, an attempt is made to understand the basis of the groupings, drawing on environmental features (table 5 in Dreccer et al. 2007) and trait information (Tables 2 and 3, Fig. 3). A correlation analysis was conducted between the loadings of the different sites in the 2 factors retained in the factor analytic model analysis (Fig. $1 a-c$ ) and the crop stage-based environmental variables (Table 3). The information on crop attributes ranged from flowering dates and 1000-grain weights in METShip1, to a more extensive phenotypic characterisation in METShip3. Principal component analysis was used to relate yields and trait information (Fig. 3).

\section{METShip 1}

A strict interpretation of Table 3 suggests that frost-inducing temperatures during flowering and water availability from sowing to flowering and during grain filling were the environmental descriptors contributing significantly to the discrimination of groups of lines across sites (Table 3). However, it is more likely that differences in flowering dates, a major factor underpinning adaptation, were responsible for the response of the lines to the different environments, as discussed below (Fig. 3). None of the sites except $02 \mathrm{HshamIRR}$, recorded below $0^{\circ} \mathrm{C}$ temperatures, and water availability ranged from $94 \mathrm{~mm}$ at $02 \mathrm{Mdin}$ to $448 \mathrm{~mm}$ at 02HshamIRR, with $206 \mathrm{~mm}$ at CIANO (Dreccer et al. 2007).

The multivariate analysis of yield and flowering dates had 3 principal components with eigenvalues greater than 1 (Fig. $3 a$ ). The first three principal components explained c. $41 \%, 17 \%$, and $12 \%$ (not presented) of the variation in the data, respectively. Grain weight recorded at $02 \mathrm{HshamIRR}$ did not contribute significantly to the analysis and is presented separately in Table 2. In general, earlier flowering lines, such as those in Groups 1, 4, and 5, were higher yielding in Biloela, Roma, Merredin, and CIANO, while yields in Horsham and Wongan Hills did not show any relationship with maturity type (Fig. $3 a$, Table 2). The poorest performing Group 2 lines were late flowering at Biloela and Roma and intermediate at Horsham. In comparison, the Group 1 materials were broadly adapted and early flowering across locations, whereas groups with specific adaptation to the south (Groups 6 and 3) were early to intermediate flowering at Horsham and intermediate to late in the north. Consistent with these results, the sister lines from this METShip1 that showed divergent performance in the previous section, AUS29543 (Group 1) and AUS29539 (Group 2), were scored as intermediate and very late, respectively, in Biloela and Horsham. Similarly, AUS29616 (Group 1) and AUS29598 (Group 2) were, respectively, scored as early and intermediate across locations (data not presented).

It is plausible that lines showing broad (Group 1) or northern adaptation (Group 5) have a low requirement for vernalisation and/or photoperiod, since they were classified as early flowering with respect to the checks in both the north (Biloela: -24.38 lat.) and the south (Horsham: -36.65 lat.) of Australia. For example, the sister lines from the family CHEN/AEGILOPS TAUSCHII// TURACO/4/HERPRO//CMH75A.66/SERI/3/CMH76.173/CN O79 were consistently early in Biloela, Roma, and Horsham (data not presented). The range of sowing dates from northern to southern Australia minimised the differences in photoperiod during the vegetative stage (up to 600 degree-days from sowing) among the trials grown in different regions (from $10.1 \mathrm{~h}$ in Horsham to $10.7 \mathrm{~h}$ in Roma); hence, photoperiod sensitivity of the lines cannot be evaluated. For the same 
period, minimum temperatures were $1.0,2.7$, and $4.0^{\circ} \mathrm{C}$ in Roma, Horsham, and Biloela, respectively. It is likely that some lines in Group 6, with specific adaptation to Horsham, such as OCI// TJB368.251/BUC/3/CROC_1/AEGILOPS TAUSCHII (205)// KAUZ/4/NL 682, had some sensitivity to vernalisation since they were scored as close to early (1.3), intermediate (2), and close to late (2.7) in Roma, Horsham, and Biloela, respectively, following the pattern of minimum temperatures.

Figure $3 a$ suggests that earliness played a role in adaptation in the northern locations and CIANO but was not clearly associated with higher yields in Horsham. However, it is worth mentioning that while the trials at CIANO and the north were grown on stored

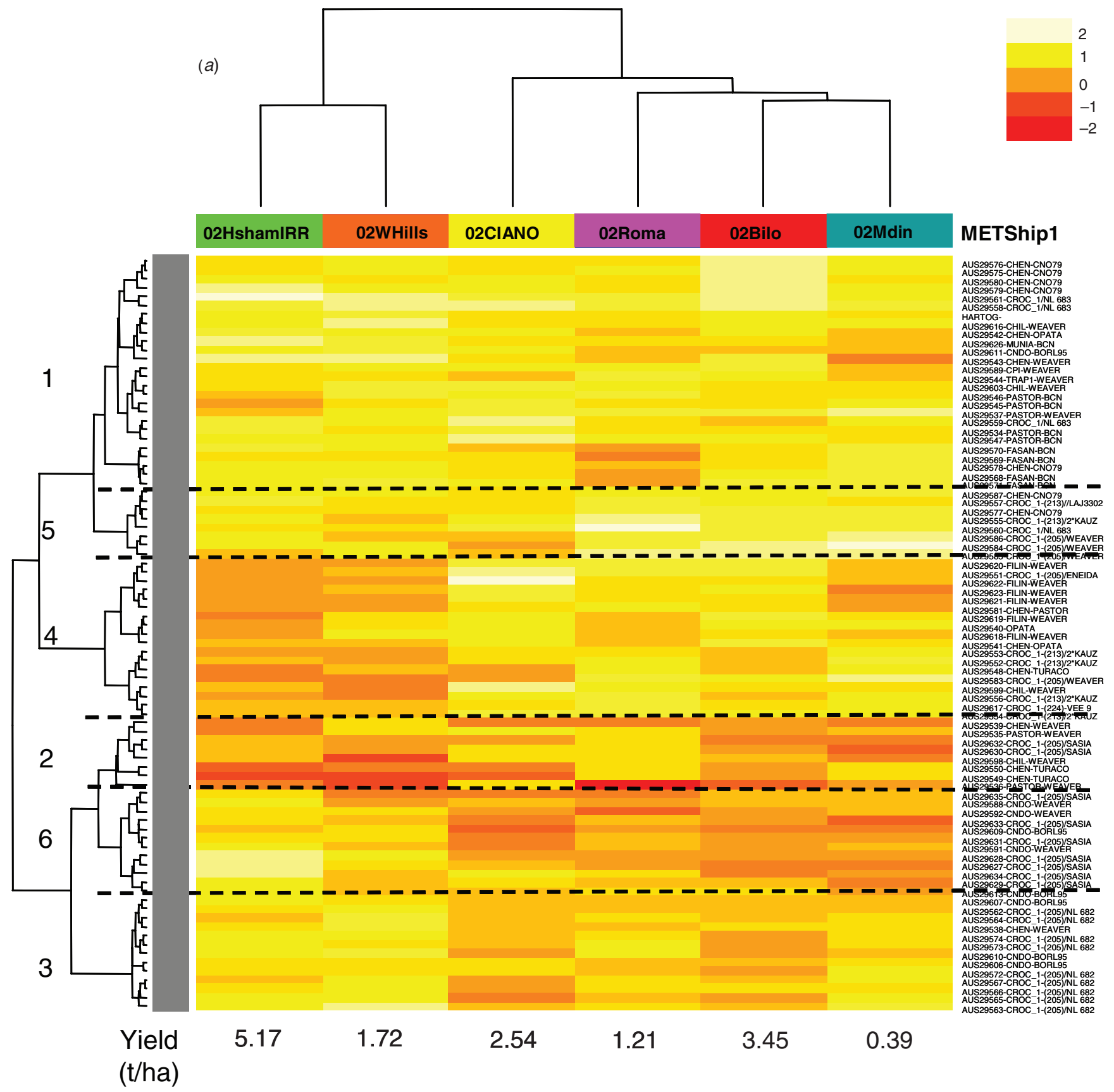

Fig. 2. Heat-maps based on yield BLUPs for (a) METShip1, (b) METShip2, and (c) METShip3. Numbers to the left of the graph indicate cluster number as referred to in the text. Pedigrees have been abbreviated to AUS number plus last cross in the pedigree. First portion of pedigree was added if the recurrent parent was the same in different families. Full pedigrees can be looked up in the Accessory Publication, based on the AUS numbers shown here. Red hues represent below-average performance, while above-average is represented by light yellow-white hues (see on the Figure). The range of the standardised difference between the line and the site mean yield was -4.2 to 2.6 in METShip1, -2.8 to 2.9 in METShip2, and -2.6 to 2.0 in METShip3. Yields indicated below a site column indicate site means. 
moisture in one of the driest years on record in Australia (2002, www.bom.gov.au/cgi-bin/silo/reg/cli_chg/timeseries.cgi), the Horsham site was irrigated. The flowering date information supports the idea that in a very dry year, early flowering lines use available water more efficiently by increasing the proportion of water transpired during the reproductive period $v$. the whole cycle (Sadras and Connor 1991), leading to higher yields.

\section{METShip2}

In METShip2, only the evapotranspiration over different periods showed any relationship with the spread of lines in Fig. $1 b$, albeit at a low level of significance $(P<0.1)$; the remaining environmental data were inconclusive
(Table 3). From the multivariate analysis of traits and yields in METShip2, eigenvalues of 5 principal components were greater than 1, the first two explaining a relatively small portion of variation, $26 \%$ and $16 \%$, respectively (Fig. 3b). Discarded from the analysis were flowering dates in 03 HshamRF, due to narrow range of variation, and flowering dates in 03Roma, which ranked varieties similarly to 03Bilo. The span in flowering dates was smaller in this shipment than in METShip1 (Table 2) and did not explain the aforementioned difference in the performance of sister lines from the crosses PASTOR/3/ALTAR 84/AEGILOPS TAUSCHII//OPATA and CROC_1/AEGILOPS TAUSCHII (224)//OPATA/3/ PASTOR. The rank of lines for grain weight was consistent across seasons and locations and relatively independent of

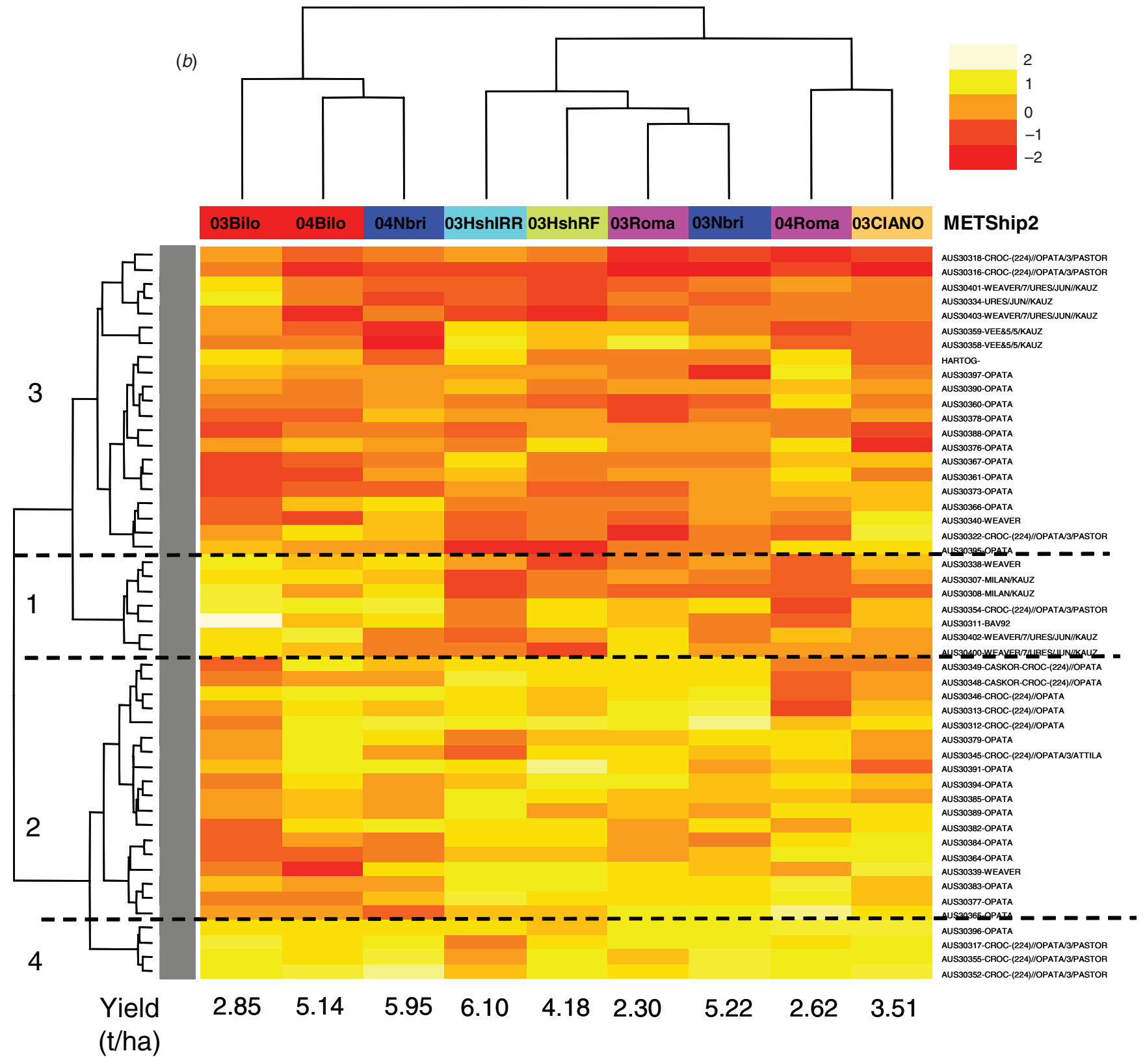

Fig. 2. (continued) 


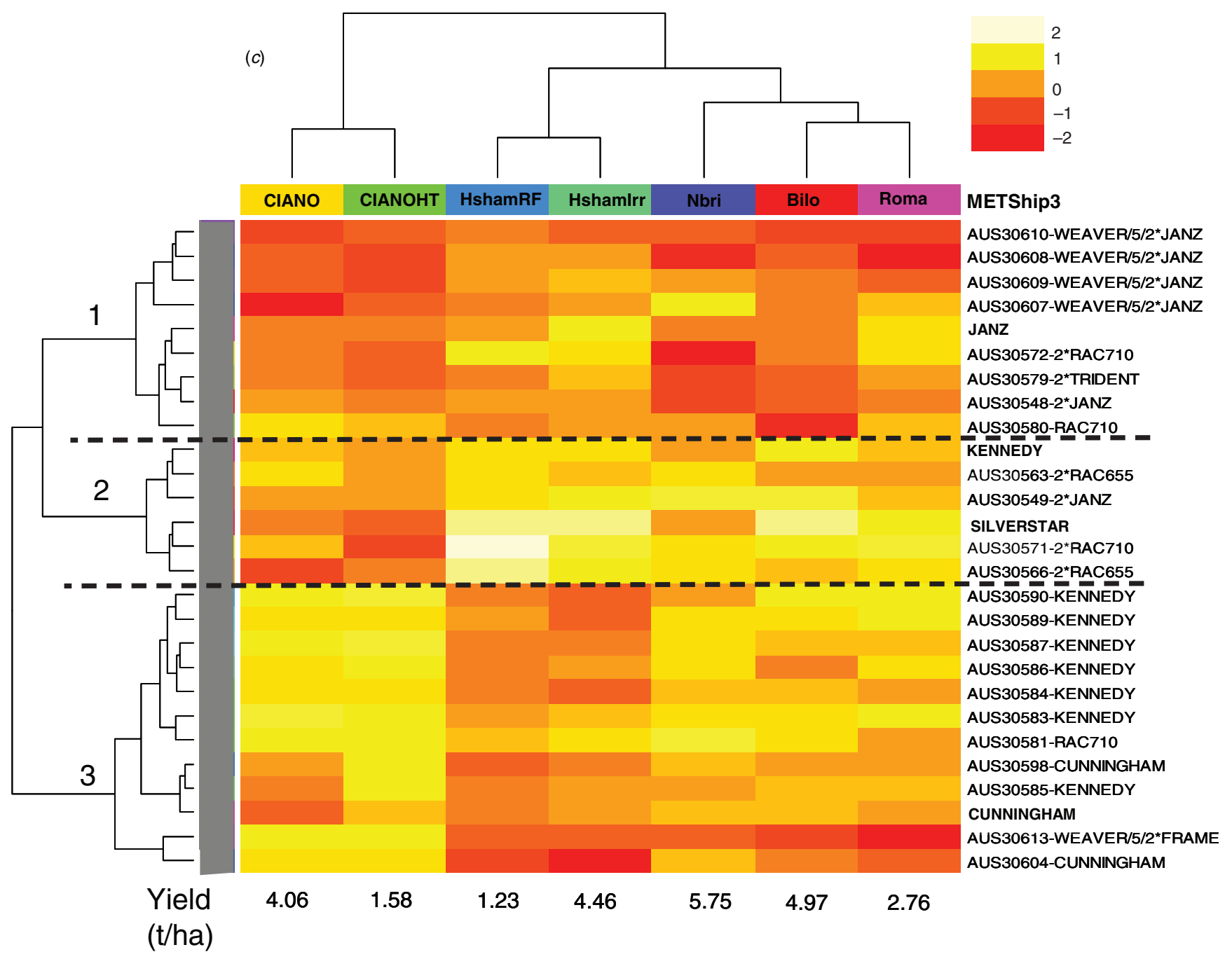

Fig. 2. (continued)

yield. Analysis beyond the scope of this paper would be required to study if the differences in grain weight arose from differences in potential grain weight, compensation with grain number per $\mathrm{m}^{2}$, or from the grain-filling environment per se.

\section{METShip3}

The third shipment of synthetics was evaluated in a comparatively drier season in the south relative to the north of Australia or CIMMYT, with seasonal water availability in the order of $232 \mathrm{~mm}$ at 04HshamRF, c. $300 \mathrm{~mm}$ at 04Bilo and 04Nbri, and $339 \mathrm{~mm}$ at 04Roma, while 04CIANO received $400 \mathrm{~mm}$. Despite this, the most significant factors explaining the $\mathrm{G} \times \mathrm{E}$ interaction as characterised by the loadings on the first factor in Fig. 1c were the level of diffuse radiation, the vapour pressure deficit around flowering, and temperature in the early growth stages (Table 3). Water use during flowering and grain filling only contributed to the spread of genotypes at different sites in the second factor, as did extreme high temperature during flowering (probably discriminating in terms of susceptibility to sterility) and, to a lesser extent, day-length during the vegetative period (Table 3 ).

During flowering, the proportion of diffuse radiation was highest at 04HshamIRR (0.49) and lowest at 04CIANO (0.17). The vapour pressure deficit at this time was $1.1 \mathrm{kPa}$ at 04HshamIRR, 3.4 and $2.7 \mathrm{kPa}$ at 04CIANOHT, and 04CIANO, respectively, and ranged from 1.3 to $1.7 \mathrm{kPa}$ at the remaining sites. The temperature during the vegetative period was c. $8^{\circ} \mathrm{C}$ at $04 \mathrm{Hsham}$ irrigated and rainfed and $17.6^{\circ} \mathrm{C}$ at 04CIANO. Given the signs of the correlations (Table 3), some lines improved their relative performance under low temperatures during the vegetative stage (e.g. Horsham compared with CIANO), when the vapour pressure deficit was low and the proportion of diffuse radiation was high around flowering. Sites in the north of Australia have a comparatively high vapour pressure deficit and lower diffuse radiation than those in the south (Rodriguez and Sadras 2007). Since vapour pressure deficit and diffuse radiation are often negatively correlated (Rodriguez and Sadras 2007), it is also possible that the lines were responding to only one of these factors. High diffuse radiation enhances 
Table 3. Correlation between loading weights from Fig. 1 on yield analysis and environmental variables

\begin{tabular}{|c|c|c|c|c|c|c|c|c|}
\hline \multirow[t]{2}{*}{ Crop stage } & & & \multicolumn{2}{|c|}{ METShip1 } & \multicolumn{2}{|c|}{ METShip2 } & \multicolumn{2}{|c|}{ METShip3 } \\
\hline & & & Load 1 & Load 2 & Load 1 & Load 2 & Load 1 & Load 2 \\
\hline \multirow{5}{*}{$\begin{array}{l}\text { Vegetative } \\
\text { (600 degree-days) }\end{array}$} & Temperature & ${ }^{\circ} \mathrm{C}$ & -0.564 & -0.546 & -0.161 & -0.225 & $-0.779^{\mathrm{B}}$ & 0.431 \\
\hline & Daylength & $\mathrm{h}$ & -0.645 & $-0.769^{\mathrm{B}}$ & -0.406 & 0.150 & -0.471 & 0.780 \\
\hline & Water availability ${ }^{\mathrm{A}}$ & $\mathrm{mm}$ & 0.152 & 0.098 & -0.443 & 0.044 & -0.582 & 0.672 \\
\hline & Evapotranspiration $^{\mathrm{A}}$ & $\mathrm{mm}$ & -0.066 & -0.295 & -0.411 & 0.539 & -0.067 & 0.403 \\
\hline & $\mathrm{ET}: \mathrm{WA}^{\mathrm{A}}$ & & -0.366 & -0.373 & -0.008 & 0.311 & 0.583 & -0.305 \\
\hline \multirow{9}{*}{$\begin{array}{l}\text { Around flowering } \\
\qquad \begin{array}{l}(-300 \text { to }+100 \\
\text { degree-days })\end{array}\end{array}$} & Temperature & ${ }^{\circ} \mathrm{C}$ & -0.632 & -0.884 & -0.140 & -0.152 & -0.203 & 0.603 \\
\hline & Freq. temp $\leq 0^{\circ} \mathrm{C}$ & & 0.961 & 0.553 & -0.232 & 0.340 & 0.522 & 0.056 \\
\hline & Freq. temp $\geq 30^{\circ} \mathrm{C}$ & & -0.352 & -0.505 & -0.345 & 0.035 & -0.341 & 0.803 \\
\hline & Fraction diffuse radiation & & -0.008 & 0.348 & -0.149 & 0.462 & $\underline{0.912}^{\mathrm{B}}$ & -0.438 \\
\hline & Vapour pressure deficit & $\mathrm{kPa}$ & 0.008 & -0.549 & -0.034 & -0.133 & -0.824 & 0.726 \\
\hline & Photothermal quotient & $\mathrm{MJ} /{ }^{\circ} \mathrm{C}$ & 0.330 & 0.715 & -0.040 & 0.333 & -0.365 & 0.519 \\
\hline & Water availability ${ }^{\mathrm{A}}$ & $\mathrm{mm}$ & 0.881 & 0.210 & -0.366 & 0.279 & -0.327 & 0.846 \\
\hline & Evapotranspiration $^{\mathrm{A}}$ & $\mathrm{mm}$ & 0.036 & -0.528 & -0.536 & 0.555 & -0.035 & 0.352 \\
\hline & $\mathrm{ET}: \mathrm{WA}^{\mathrm{A}}$ & & -0.662 & -0.164 & -0.052 & 0.203 & 0.429 & -0.588 \\
\hline \multirow{5}{*}{$\begin{array}{l}\text { Grain filling } \\
\quad \text { (600 degree-days) }\end{array}$} & Temperature & ${ }^{\circ} \mathrm{C}$ & -0.550 & -0.624 & 0.109 & -0.263 & -0.607 & 0.645 \\
\hline & Freq. temp $\geq 30^{\circ} \mathrm{C}$ & & -0.370 & -0.558 & 0.100 & 0.029 & -0.615 & 0.620 \\
\hline & Water availability ${ }^{\mathrm{A}}$ & $\mathrm{mm}$ & 0.921 & 0.316 & -0.337 & 0.264 & -0.324 & 0.860 \\
\hline & Evapotranspiration $^{\mathrm{A}}$ & $\mathrm{mm}$ & 0.021 & -0.738 & -0.527 & 0.606 & -0.068 & 0.394 \\
\hline & $\mathrm{ET}: \mathrm{WA}^{\mathrm{A}}$ & & -0.703 & -0.262 & -0.020 & 0.153 & 0.409 & -0.718 \\
\hline
\end{tabular}

${ }^{\mathrm{A}}$ From sowing and up to corresponding period.

${ }^{\mathrm{B}}$ Using a 2-tailed test: in bold, significant values at $\alpha=0.05$; in bold and underlined, significant values at $\alpha=0.01$; in italics, significant values at $\alpha=0.10$.

radiation-use efficiency by increasing the contribution of lower canopy layers to dry-matter production, particularly in canopies with erect leaves and well distributed leaf nitrogen content (Hammer and Wright 1994; Dreccer et al. 1998). High vapour pressure deficit reduces the realised water-use efficiency (Tanner and Sinclair 1983; Rodriguez and Sadras 2007), independently of the genetic potential for transpiration efficiency. At high vapour pressure deficit, stomata close, transpiration is reduced, the $\mathrm{CO}_{2}$ concentration inside the leaf interior decreases and, often, the rate of photosynthesis drops. Genotypic variation has been reported for mechanisms regulating the transpiration rate, which could be behind the observed differential response to vapour pressure deficit. Among them is stomatal conductance (Condon et al. 2002; Fischer et al. 1998) and plant hydraulic conductance as modulated by the diameter of xylem vessels in the seminal roots (Richards and Passioura 1981).

To study the association between yield and traits in METShip3, 5 lines (AUS30549, AUS30607, AUS30608, AUS30610, and AUS30566) were omitted from the analysis due to lack of records (except for yield and grain weight) at the Horsham rainfed and irrigated sites. Some variables showing little variation (e.g. height in 04HshamRF) were not included, and only one of any two variables giving reasonably similar information (e.g. spike and stem number) was retained to avoid over-fitting the model (Fig. 3c). The 3 groups of lines identified in METship3 were scored as intermediate in flowering at CIANO. Yields were negatively correlated with flowering dates at Biloela $(y[\mathrm{t} / \mathrm{ha}]=31.2-0.3 x[\mathrm{~d}], r=0.52, n=27$, $P<0.01$ ), but the association between these 2 variables was not significant at Horsham, where the range of flowering dates was relatively narrow in that year (Table 2).
High yields at Horsham and in the northern region, i.e. Group 2, were related to cooler canopies, i.e. low values of the canopy stress index (CSI), measured around anthesis and early grain filling at $04 \mathrm{HshamRF}$ (Fig. $3 c$, Table 2). The CSI, an indicator of transpiration, is expected to be positive and high when the canopy has a reduced capacity to dissipate heat; in this instance, high stomatal closure is expected under high vapour pressure deficit and/or low water supply. A range of traits could be behind the cooler canopies of the higher yielding lines in Horsham, from differential stomatal sensitivity, as mentioned previously, to differential access to water. Reynolds et al. (2007) showed a higher yield and biomass of SBWs in Australian background compared with the recurrent parents, when grown on stored soil moisture at CIANO. This was associated with an increased partitioning of root mass to deeper soil profiles $(0.60-1.20 \mathrm{~m})$, leaving less residual moisture at those depths.

The taller SBWs (Group 3 was $>100 \mathrm{~cm}$ in height) with a relatively higher ground cover capacity were successful at CIANO, and these lines also had a higher concentration of water-soluble carbohydrates (WSC) in the stem and lower stem number per unit area when scored at 04Hsham (Fig. 3c, Table 2). Richards (1992a) had reported the height interval for optimum yield in rainfed spring wheat to be $70-100 \mathrm{~cm}$. It is worth noting that all the core SBWs in METShip3 were semidwarfs, with most containing the Rht-B1b (Rhtl) allele, except for 4 lines in Group 2 (Kennedy, AUS30563, AUS30571, and AUS30566), which had Rht-D1b (Rht2) (R. Trethowan, pers. comm.). Thus, despite all of them being semi-dwarf wheats, significant differences in height were recorded among the groups, with successful lines at CIANO tending to be the tallest among the semi-dwarfs. A background effect on the reduction in height attributed to $R h t-B 1 b$ and $R h t-D 1 b$ 

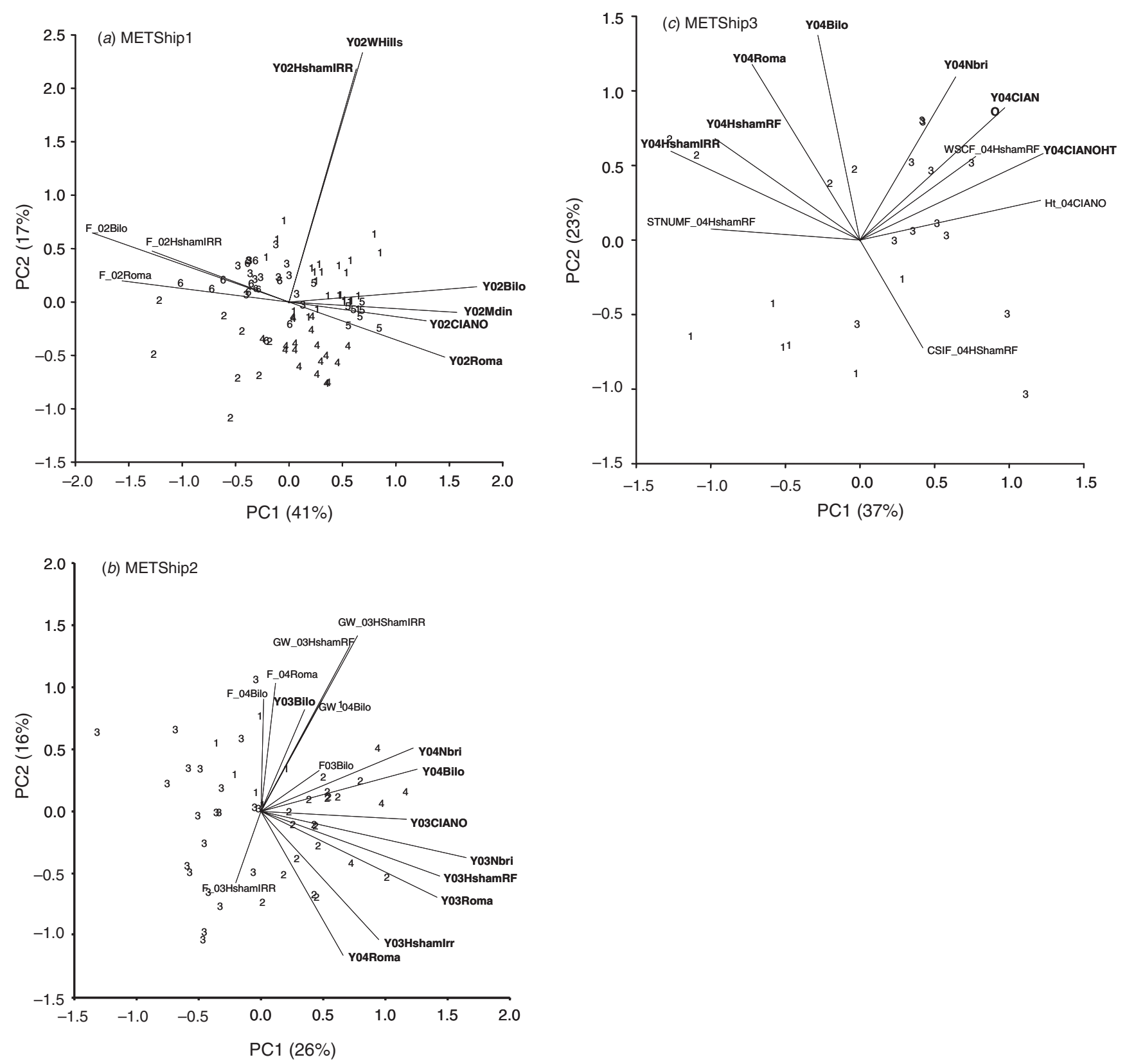

Fig. 3. Biplots of core SBWs and checks (scores) identified by their group number (as per Fig. 2) as characterised by measured traits per site (loadings, capital letters) for (a) METShip1, (b) METShip2, and (c) METShip3. F, Flowering (per category or in days after flowering, see Table 2); Y, yield (t/ha); GW, 1000-grain weight (g); STNUMF, stem number at flowering $\left(\right.$ per $\left.\mathrm{m}^{2}\right)$; CSIF, canopy stress index at flowering around flowering $\left({ }^{\circ} \mathrm{C} / \mathrm{kPa}\right) ; \mathrm{Ht}$, height $($ per class or in $\mathrm{cm}$, see Table 2); WSCF, water-soluble carbohydrates at flowering (\%).

(Richards 1992a; Mathews et al. 2006) is unlikely, as no differences in height between yield-based groups were evident in the two contrasting Horsham environments (Table 3). Alternatively, the SBWs could have genotypic variability for elongation and expansion processes in response to stress, independent from the regulation of height by major reduced-height genes. In contrast to Horsham, plants at CIANO were grown in beds on stored soil moisture and were gradually exposed to water stress towards flowering; therefore, the range in heights observed between groups ( $30 \mathrm{~cm}$ or more) could reflect the effects on the elongation of the last internodes. Differences in height defined during that period may also reflect differential access to water, either related to 'water saving' strategies earlier in the season (e.g. via higher ground cover or earlier flowering) or enhanced access to water via increased root mass or length at depth (Manschadi et al. 2006; Reynolds et al. 2007).

Most SBWs from Group 3, which performed above average at CIANO and below average in southern Australia, also had a slight but consistently higher concentration of WSC in the stem at anthesis in 04HshamRF (Fig. 3c, Table 2). The benefit of this trait 
at CIANO is consistent with the terminal drought stress characteristic of their nursery (Blum 1998; Reynolds et al. 2007). In Fig. 3c, height at 04CIANO and the concentration of WSC at 04HshamRF seem to be positively correlated. Whether or not taller stems represent an increase in the total amount of WSC per $\mathrm{m}^{2}$ available for grain growth under terminal drought is not clear from previous reports, due to compensation between differences in height and storage capacity per unit length (see discussions in Richards 1992b; Borrell et al. 1993; Shearman et al. 2005). In our study, the concentration of WSC in the stem was negatively correlated with the stem number per $\mathrm{m}^{2}$ in 04HshamRF $\left(y[\%]=27.8-0.0135 x\left[\# / \mathrm{m}^{2}\right], r=0.48, n=22\right.$, $P<0.05$ ) (Fig. $3 c$, Table 3). In other words, it appears that lines which used more WSC to fill the grain had a lower tillering capacity. This phenotype could be more efficient at allocating resources when plants are grown on stored moisture, reducing the allocation of resources to organs that will not sustain a spike. The microsatellite marker (Xgwm 136) indicative of the presence of a major tiller inhibition gene, tin, on chromosome 1A (Spielmeyer and Richards 2004), was not present in any of the core SBWs (Lynne McIntyre, pers. comm.) and does not, therefore, explain any of the observed variation. The conventional cultivation system at CIANO, where densities are comparatively higher than in Australia (300 v. 150 plants $/ \mathrm{m}^{2}$ ), may increase the chance of selecting lines with limited tillering capacity.

\section{Conclusions}

Early flowering appears to be important to achieving broad adaptation in the northern Australian wheatbelt. While early flowering can shift the grain-filling period to a time when average temperatures are cooler (Sadras and Monzon 2006), it can also shift water use from pre- to post-anthesis, which is critical for crops grown under limited stored soil moisture (as shown by Dreccer et al. 2002). Each extra millimetre of water used during grain filling has been calculated to produce an extra $50-60 \mathrm{~kg} / \mathrm{ha}$ of grain (Manschadi et al. 2006; Kirkegaard et al. 2007).

The divergence in performance between recurrent parents and SBWs or between sister lines was an unexpected feature of this analysis. The SBWs are advanced backcrosses, and therefore it is expected that a high proportion of the recurrent parent is present in their genome. However, in light of these results, it would be very useful to investigate which portions of the genome of the primary synthetics have remained in these lines relative to the contribution of the recurrent parents. In particular, it would be appropriate to screen genomic regions where known vernalisation and photoperiod genes are located to see if they were consistently affected by the selection process.

Selection for yield at CIANO did not identify the best lines for northern Australia, but rather identified the average-performing ones (Fig. 2). For instance, in METShip1, the highest yielding group at CIANO was Group 1 compared with Group 5 in the north (Fig. 2a). Similarly, in METShip3, Group 3 was the highest yielding at CIANO but Group 2 was the highest yielding in the north (Fig. 2c). Thus, despite the many similarities between these environments (Dreccer et al. 2007) there is a need to investigate factors controlling specific adaptation to the northern region. In addition, groups of lines with specific adaptation to the south would not have been identified by selecting the highest yielding lines at CIANO (Fig. 2c), even when the mean yields of the sites were similar, e.g. 4.1 and 4.4 t/ha at 04CIANO and 04HshamIRR, respectively. More importantly, lines evaluated at Horsham under rainfed $(250-300 \mathrm{~mm})$ or irrigated conditions (c. $550 \mathrm{~mm}$ ), ranked similarly. This may be a consequence of the selection process at CIMMYT per se, since SBWs are selected under alternating rainfed and irrigated cycles (Trethowan 2004; Trethowan et al. 2005) and they are expected to do well under a range of conditions. However, it also highlights the fact that the total amount of available water might not be the main factor dictating specific adaptation to the southern environments. It is possible that constitutive changes take place during selection at CIMMYT, which are not conducive to success in an environment depending on in-season rainfall. It would be worth examining if restricted tillering, due to high planting density, is one of these aspects.

The implications of these findings are that to optimise selection at CIMMYT for Australian environments, selection could be either trait based or yield data combined with trait information. Flowering date, canopy temperature around flowering, tiller density, and water-soluble carbohydrate concentration in the stem at flowering seem likely candidates.

\section{Acknowledgments}

The authors acknowledge the support of the Australian Grains Research and Development Corporation, the Department of Primary Industries, Victoria, and CIMMYT for funding the field work component of this research. We are very grateful to the Australian plant breeders R. Eastwood, J. Sheppard, B. Winter, R. Wilson, and M. Lu for coordinating and collecting data in the field experiments. MFD and FCO also thank J. Bull for excellent technical assistance. We thank L. McIntyre and J. Drenth for running the Xgwm136 marker on the lines.

\section{References}

Blum A (1998) Improving wheat grain filling under stress by stem reserve mobilisation. Euphytica 100, 77-83. doi: 10.1023/A:1018303922482

Borrell AK, Incoll LD, Dalling MJ (1993) The influence of Rht 1 and $R h t 2$ alleles on the deposition and use of stem reserves in wheat. Annals of Botany 71, 317-326. doi: 10.1006/anbo.1993.1041

Braun HJ, Rajaram S, van Ginkel M (1996) CIMMYT's approach to breeding for wide adaptation. Euphytica 92, 175-183. doi: 10.1007/BF00022843

Condon AG, Richards RA, Rebetzke GJ, Farquhar GD (2002) Improving intrinsic water use efficiency. Crop Science 42, 122-131.

Cooper M, deLacy IH (1994) Relationships among analytical methods used to study genotypic variation and genotype-by-environment interaction in plant breeding multi-environment experiments. Theoretical and Applied Genetics 88, 561-572. doi: 10.1007/BF01240919

de la Vega AJ, Chapman SC (2001) Genotype by environment interaction and direct selection for yield in sunflower. II Three-mode principal component analysis of oil and biomass yield across environments in Argentina. Field Crops Research 72, 39-50. doi: 10.1016/S0378-4290 (01)00163-0

Dreccer MF, Borgognone MG, Ogbonnaya FC, Trethowan RM, Winter B (2007) CIMMYT-selected derived synthetic bread wheats for rainfed environments: yield evaluation in Mexico and Australia. Field Crops Research 100, 218-228. doi: 10.1016/j.fcr.2006.07.005

Dreccer MF, Rodriguez D, Ogbonnaya F (2002) Tailoring wheat for marginal environments: a crop modelling study. In 'Proceedings of the 12th Australasian Plant Breeding Conference'. September 2002, Perth, W. Aust. (Ed. JA McComb) pp. 457-462. (The Australasian Plant Breeding Association, Inc.: Perth) 
Dreccer MF, Slafer GA, Rabbinge R (1998) Optimisation of vertical distribution of canopy nitrogen: an alternative trait to increase yield potential in winter cereals. In 'Crop Sciences: Recent Advances'. (Ed. AS Basra) pp. 47-77. (The Haworth Press, Inc.: New York)

Fischer RA (1985) Number of kernels in wheat crops and the influence of solar radiation and temperature. Journal of Agricultural Science 105, 447-461.

Fischer RA, Rees D, Sayre KD, Lu Z-M, Condon AG, Larque Saavedra A (1998) Wheat yield progress associated with higher stomatal conductance and photosynthetic rate, and cooler canopies. Crop Science 38, 1467-1475.

Goudriaan J, van Laar HH (1994) 'Modelling potential growth processes.' (Kluwer Academic Publishers: Amsterdam)

Hammer GL, Wright GC (1994) A theoretical analysis of nitrogen and radiation effects on radiation use efficiency in peanut. Australian Journal of Agricultural Research 45, 575-589. doi: 10.1071/AR9940575

Idso S (1982) Non-water-stress baselines: a key to measuring and interpreting plant water stress. Agricultural and Forest Meteorology 27, 59-70.

Idso SB, Jackson RD, Pinter PJ Jr, Moran MS, Reginato RJ, Hartfield JL (1981) Normalising the stress-degree-day parameter for environmental variability. Agricultural Meteorology 24, 45-55. doi: 10.1016/ 0002-1571(81)90032-7

Kirkegaard JA, Lilley JM, Howe GN, Graham JM (2007) Impact of subsoil water use on wheat yield. Australian Journal of Agricultural Research 58, 303-315. doi: 10.1071/AR06285

Loss SP, Kirby EJM, Siddique KHM, Perry MW (1989) Grain growth and development of old and modern Australian wheats. Field Crops Research 21, 131-146. doi: 10.1016/0378-4290(89)90049-X

Manschadi AM, Chrsitopher J, deVoil P, Hammer GL (2006) The role of architectural traits in adaptation of wheat to water-limited environments. Functional Plant Biology 33, 823-837. doi: 10.1071/FP06055

Mathews KL, Chapman SC, Trethowan R, Singh RP, Crossa J, Pfeiffer W, van Ginkel M, DeLacy I (2006) Global adaptation of spring bread and durum lines near-isogenic for major reduced height genes. Crop Science 46, 603-613. doi: 10.2135/cropsci2005.05-0056

Miralles DJ, Ferro BC, Slafer GA (2001) Developmental responses to sowing date in wheat, barley and rapeseed. Field Crops Research 71, 211-223. doi: 10.1016/S0378-4290(01)00161-7

R Development Core Team (2006) 'R: A language and environment for statistical computing.' (R Foundation for Statistical Computing: Vienna, Austria) (Available at: www.R-project.org)

Rajaram S, van Ginkel M (2001) Mexico: 50 years of international wheat breeding. In 'The World Wheat Book'. (Eds AP Bonjean, WJ Angus) (Lavoisier Publishing: Paris)

Reynolds M, Dreccer MF, Trethowan R (2007) Drought adaptive traits derived from wheat wild relatives and landraces. Journal of Experimental Botany 58, 177-186. doi: 10.1093/jxb/erl250

Reynolds M, Trethowan R, Crossa J, Vargas M, Sayre KD (2002) Physiological factors associated with genotype by environment interaction in wheat. Field Crops Research 75, 139-160. doi: 10.1016/ S0378-4290(02)00023-0

Richards RA (1992a) The effect of dwarfing genes in spring wheat in dry environments. I. Agronomic characteristics. Australian Journal of Agricultural Research 43, 517-527. doi: 10.1071/AR9920517

Richards RA (1992b) The effect of dwarfing genes in spring wheat in dry environments. II. Growth, water use and water use efficiency. Australian Journal of Agricultural Research 43, 529-542. doi: 10.1071/AR9920529

Richards RA, Passioura JB (1981) Seminal root morphology and water use of wheat. II. Genetic variation. Crop Science 21, 253-255.

Rodriguez D, Sadras VO (2007) The limit to wheat water use efficiency in Australia. I. Theoretical and empirical basis for a benchmarking exercise. Australian Journal of Agricultural Research 58, 287-302. doi: 10.1071/ AR06135
Rodriguez D, Sadras VO, Christensen LK, Belford R (2005) Spatial assessment of wheat crops as affected by water and nitrogen supply using infrared thermal imagery. Australian Journal of Agricultural Research 56, 983-993. doi: 10.1071/AR05035

Sadras VO, Connor DJ (1991) Physiological basis of the response of harvest index to the fraction of water transpired after anthesis - a simple model to estimate harvest index for determinate species. Field Crops Research 26, 227-239. doi: 10.1016/0378-4290(91)90001-C

Sadras VO, Monzon JP (2006) Modelled wheat phenology captures rising temperature trends: shortened time to flowering and maturity in Australia and Argentina. Field Crops Research 99, 136-146. doi: 10.1016/j. fcr.2006.04.003

Shearman VJ, Sylvester-Bradley R, Scott RK, Foulkes MJ (2005) Physiological processes associated with wheat yield and progress in the UK. Crop Science 45, 175-185.

Smale M, Reynolds MP, Warburton M, Skovmand B, Trethowan R, Singh RP, Ortiz-Monasterio I, Crossa J, Khairallah M, AlmanzaPinzon MI (2002) Dimensions of diversity of modern spring bread wheat in developing countries from 1965. Crop Science 42, 1766-1779.

Smith A, Cullis B, Thompson R (2001) Analysing variety by environment data using multiplicative mixed models and adjustments for spatial field trend. Biometrics 57, 1138-1147. doi: 10.1111/ j.0006-341X.2001.01138.x

Spielmeyer W, Richards RA (2004) Comparative mapping of wheat chromosome $1 \mathrm{AS}$ which contains tiller inhibition gene (tin) with rice chromosome 5S. Theoretical and Applied Genetics 109, 1303-1310. doi: $10.1007 / \mathrm{s} 00122-004-1745-2$

Tanner CB, Sinclair TR (1983) Efficient water use in crop production: research or re-search? In 'Limitations to Efficient Water Use in Crop Production'. (Eds HM Taylor, WR Jordan, TR Sinclair) pp. 1-25. (American Society of Agronomy, Crop Science Society of America, Soil Science Society of America: Madison, WI)

Trethowan RM (2004) Selecting wheat with improved adaptation to moisture limited environments: CIMMYT's approach and experience. In 'Proceedings of the 54th Australian Cereal Chemistry Conference and 11th Wheat breeders Assembly'. Canberra, ACT. (Eds CK Black, JF Panozzo, GJ Rebetzke) pp. 191-194. (Cereal Chemistry Division, Royal Australian Chemical Institute: North Melbourne, Vic.)

Trethowan RM, Reynolds M, Sayre K, Ortiz-Monasterio I (2005) Adapting wheat cultivars to resource conserving farming practice and human nutritional needs. Annals of Applied Biology 146, 405-413. doi: 10.1111/j.1744-7348.2005.040137.x

van Herwaarden AF, Angus JF, Richards RA, Farquhar GD (1998) 'Haying-off', the negative grain yield response to nitrogen fertiliser. II. Carbohydrate and protein dynamics. Australian Journal of Agricultural Research 49, 1083-1093. doi: 10.1071/A97040

Wang QJ, McConachy FLN, Chiew FHS, James R, de Hoedt GC, Wright WJ (2001) Climatic atlas of Australia: maps of evapotranspiration. [Definition of evapotranspiration parameters and explanatory notes] p. 4. (Australian Bureau of Meteorology: Melbourne) (ftp://ftp.bom. gov.au/anon/home/ncc/www/evapotrans/ettext.pdf, Verified 5/1/2006)

Warburton ML, Crossa J, Franco J, Kazi M, Trethowan R, Rajaram S, Pfeiffer W, Zhang P, Dreisigacker S, van Ginkel M (2006) Bringing wild relatives back into the family: recovering genetic diversity in CIMMYT improved wheat germplasm. Euphytica 149, 289-301. doi: 10.1007/ s10681-005-9077-0

Yemm EW, Willis AJ (1954) The estimation of carbohydrates in plant extracts by anthrone. Biochemical Journal 57, 508-514.

Manuscript received 14 June 2007, accepted 14 December 2007 